\title{
DYNAMIC ALLOCATION OF ADDITIONAL HUMAN RESOURCES USING HYBRID SIMULATION
}

\author{
Sena, D. C. ; Silva, E. M. M. ${ }^{* *}$; Costa, A. P. R. ${ }^{* *}$; Montevechi, J. A. B. ${ }^{* *}$; Pinho, A. F. ${ }^{* *} \&$ \\ Miranda, R. C. \\ *Engineering Centre, Federal Rural University of Semi-Arid, 572 Francisco Mota Avenue, \\ Zip Code: 59625-900, Mossoró, RN, Brazil \\ ${ }^{* *}$ Institute of Production Engineering and Management, Federal University of Itajubá, \\ 1303 BPS Avenue, PO Box: 50, Zip Code: 37500-903, Itajubá, MG, Brazil \\ E-Mail: davidc.sena@gmail.com
}

\begin{abstract}
This work simulated several alternatives for the dynamic allocation of additional human resources in a company that produces a group of specific products. The goal was to increase the average amount of the margin of the total contribution through a hybrid application of a discrete event simulation (DES) and an agent-based modelling simulation (ABMS). Two different decision-making forms were proposed to determine which workstation should receive an additional operator. The first proposal was based on the occupancy level of the operators, while the second one was based on the intermediate queue size. The computational model was operationally validated by comparing the results with actual production data from the company. Twelve scenarios were analysed using a margin of the established contribution. Based on the occupancy rate, the ratio improved on average by $27.68 \%$, with an additional operator in the workstation. According to the second criterion, this improvement raised to $117.51 \%$.
\end{abstract}

(Received in May 2016, accepted in October 2016. This paper was with the authors 1 month for 1 revision.)

Key Words: Hybrid Simulation, Agent-Based Simulation, Discrete-Event Simulation, Resource Allocation, Food Production Process

\section{INTRODUCTION}

Companies in general constantly seek improvements in their processes so that they can increase their productivity and, therefore, their profits. For developing a model for simulation, analysing what someone wants to simulate is necessary so that it will coincide with the real system. Different types of systems are studied using discrete simulation of event(s) because of yours relevance for many areas, e.g. manufacturing, public service, and health systems among others [1].

Although the simulation of a discrete event is quite comprehensive, some systems are very complex and, hence, the traditional tools have not been sufficient to analyse them [2]. Regarding this aspect, and according to [3], agent-based simulation (ABS) is a technique applied to capture emergent phenomena that result from the interaction of independent entities. This, by definition, cannot be reduced to parts of the system because of the interaction among them. For [4], the agents also interact with their local environment through the simple internal rules for decision making processes, the movement and action. The overall behaviour of the simulated system is the result of a dense interaction between relatively simple behaviours.

A simulation based on agents was observed to be utilized recently to support decision making in the real world, as indicated by several articles in literature. The following articles are examples: in [5] the authors synchronized the manufacturing agents on a JADE ${ }^{\text {TM }}$ platform of a shop floor controller using the hybrid communication protocols in the simulation; Zhang [6] simulated an agent-based model to answer how the technological information of the supply chain emerges and diffuses between suppliers and manufacturers. 
He created these experiments using the diffusion processes of two types of innovation in the competitive technology.

The objective of this study was the proposal of alternatives for the decision making process to support the dynamic allocation of additional resources, which could increase the margin of the total contribution of a specific line, utilizing a hybrid simulation (i.e., combination of discrete event and agent-based simulations). The hybrid simulation could cover the discrete and behavioural aspects of this work. These proposals were made in a company that produces a variety of products derived from the Pupunha palm. To fulfil the objective of the hybrid simulation, two forms of the decision-making stage were analysed. The first one determined which workstation should receive an additional employee in accordance to the occupancy level. Then, the second alternative took into consideration the size of the queue.

This work is developed as follows: the introduction, the theoretical foundation, the methodology of the research, the application of the modelling and simulation method, results, conclusion, acknowledgements and references.

\section{THEORETICAL FOUNDATION}

\subsection{Discrete event simulation}

Simulation has been, for many decades, one of the most popular techniques to support decision making. In [7], the discrete event simulation (DES) is a representation of a system over time, wherein the state variables change instantaneously at separate time points. The simulation model must be verified and validated through various tests, evaluations and comparisons with the real system being studied [8].

Several authors report the advantages of simulation including the analysis of complex manufacturing systems based on more effective cost. Simulation also allows the design of realistic models to represent important features of the system and to perform complex interactions among the different variables. Finally, simulation models can directly address performance measures used in the real system $[9,10]$.

In this article, the DES was used to capture the queue behaviour of a production system. This capture is essential to reflect the consequences of actions taken in the state variables. Another reason for the use of simulation, according to [10], is that it is the most recommended method for a very complex system, thereby negating the need for the traditional tools of operations research.

\subsection{Agent-based simulation}

The agent-based modelling and simulation (ABMS) has its historical roots in the study of complex adaptive systems (CAS), originally motivated by research on adaptation and emergence of biological systems. In addition to learning over time to respond effectively to new situations, one of the key features of a complex adaptive system is its ability to adapt in a changing environment [2].

According to [11], for practical purposes of modelling, it is considered that the agents have certain properties and attributes, such as modularity, autonomy, sociability and compliance. In this article, the properties used were mainly modularity and autonomy, which guarantee the independence of the agent ahead of other elements of the system. For [12], ABMS is a bottom-up approach, whereas, it can be argued that system dynamics (SD) and DES are top-down approaches to modelling systems. In addition, according to the author, the concept of an agent used in our work is an individual agent with limited interaction and without adaptability during simulation. 
When ABMS is applied to human systems, [3] summarizes that the interactions between agents are complex, nonlinear, discontinuous or discrete, the space is crucial and their position is not fixed. Since the population is heterogeneous, so are its interactions, therefore the agents show complex behaviours such as learning and adaptation. In [13] the authors modelled the decision-making agent to purchase goods in a supply chain using the reinforcement learning artificial intelligence tool.

\subsection{Related researches}

The main focus of this article is the hybrid simulation involving the DES and ABS. Conducting a research on the Scopus ${ }^{\circledR}$ database using the terms "discrete-event simulation" and "agent-based simulation" or "agent-based simulation", while limiting the search to the title, abstract and keywords, it is demonstrated in Fig. 1 that there is a growth in the number of works published in the last 15 years that associate these two types of simulation. However, the number of works is still small, even if it is increasing.

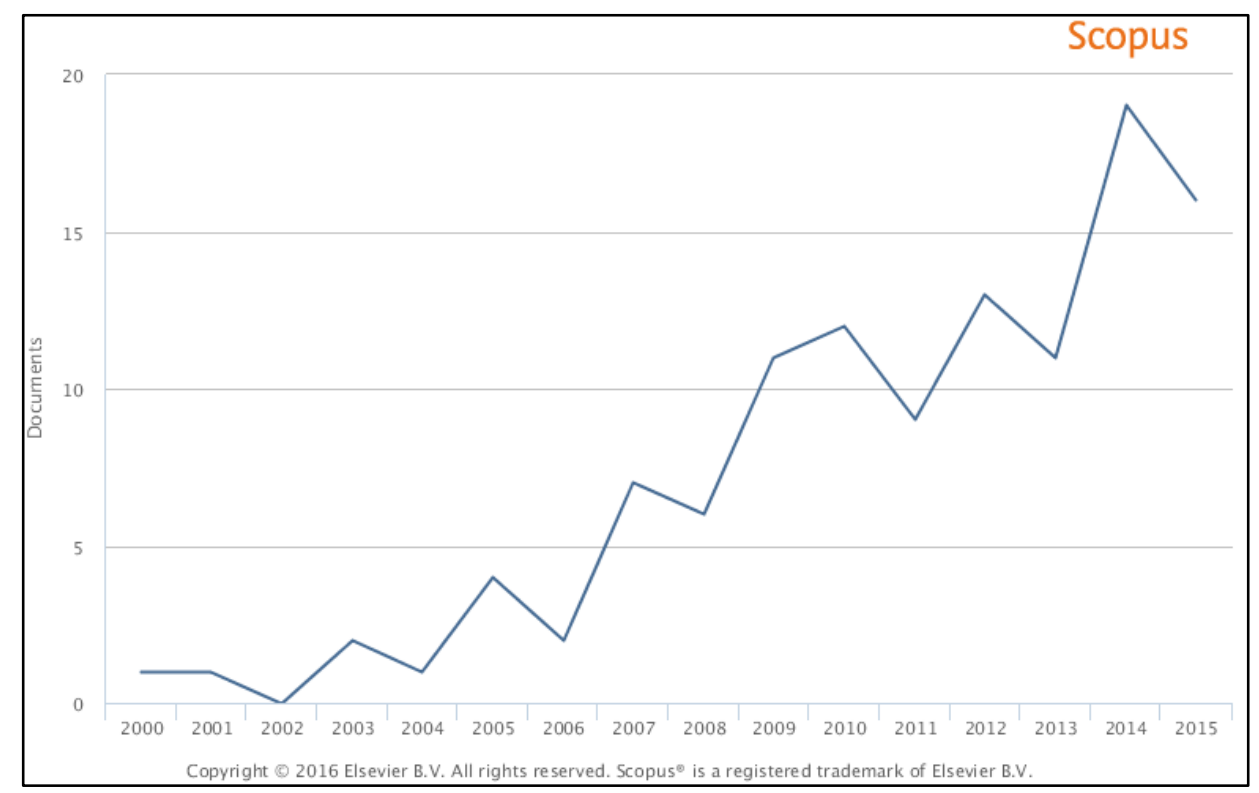

Figure 1: Number of articles published in a year.

The hybrid modelling and simulation has been used in a few and more recent articles. The main focus of the hybrid approach is to combine the advantages of two or more simulation methods, complementing one technique with another. Hao and Shen [14] mention that the hybrid approach was used to implement the simulation of the system for material handling by combining the discrete event and the agent-based modelling. Using the AnyLogic ${ }^{\mathrm{TM}}$ software, the agent-based models were built for a number of components (mobile or fixed) in the model of a discrete event for a simplified pulled production line with a Kanban system.

According to Zhao et al. [15] a hybrid simulation is a typical combination of DES, Dynamic Simulation (DS) and ABM. They proposed a more detailed model of a hybrid simulation than the simple structures of policy evaluations. According to the authors, the agent-based and modelling techniques of the dynamic systems were more advantageous to this study.

Wang et al. [16] used a combination of the dynamic systems DES and ABM to describe a chain model for a car supply from two manufacturers. The software used was also the AnyLogic ${ }^{\mathrm{TM}}$, wherein the model of simulation of the entire chain was examined. To prove the effectiveness of this model, the researchers used the inventory results, the inventory cost of distributors and the customer satisfaction chart. 
According to Suh [17], the ABS provides freedom in the description of a large number of suppliers, warehouses, distributors and customers at a physical person level, thus complementing the simulation of the traditional discrete event, in which these tasks are more difficult to be performed. The work of [18] did a study on the logistical operations in a food hub to analyse the delivery process for scenarios that were differently simulated. Onggo [19] studied a supply chain in countries with low and middle incomes (or productivity) based on data from the World Health Organization (WHO). He conducted a modelling of the system, without the implementation in a computer system being necessary.

The work of Wang et al. [20] has the authors conducting an analysis of the complementary cycle of life by utilizing the hybrid simulation to present a new complementary life cycle assessment (LCA) approach to address several limitations of the standard LCA methodology. The authors combined the three paradigms of a simulation DES, SD, and ABMS - to simulate scenarios with the intention of decreasing the consumption of energy and pollution.

Table I compares some of those works listed in the reference section that used the hybrid simulation to solve research problems.

Table I: Articles considering the hybrid simulation.

\begin{tabular}{|c|c|c|c|c|c|c|}
\hline Article & DES & SD & ABM & Performance measure & Area & $\begin{array}{c}\text { Simulation } \\
\text { Software }\end{array}$ \\
\hline$[14]$ & Yes & No & Yes & Material in process & Kanban & AnyLogic \\
\hline$[15]$ & No & Yes & Yes & Distributed photovoltaic (PV) & Solar energy & AnyLogic \\
\hline$[16]$ & Yes & No & Yes & $\begin{array}{c}\text { Inventory results, the } \\
\text { inventory cost of distributors } \\
\text { and the customer satisfaction }\end{array}$ & Inventory control & AnyLogic \\
\hline$[17]$ & Yes & No & Yes & $\begin{array}{c}\text { Total number of trailers, SKU } \\
\text { throughput (days), LTL fill } \\
\text { grade and Percentage of LTL } \\
\text { trailers }\end{array}$ & Distribution & AnyLogic \\
\hline$[18]$ & Yes & No & Yes & $\begin{array}{c}\text { Number of producers } \\
\text { scheduling }\end{array}$ & $\begin{array}{c}\text { Logistic operations in } \\
\text { a food hub }\end{array}$ & AnyLogic \\
\hline$[19]$ & Yes & Yes & Yes & None & Blood supply chain & None \\
\hline$[20]$ & Yes & Yes & Yes & $\begin{array}{c}\text { Energy consumption and } \\
\text { pollution }\end{array}$ & $\begin{array}{c}\text { Complementary } \\
\text { lifecycle assessment }\end{array}$ & AnyLogic \\
\hline
\end{tabular}

We utilized the procedures of: a) the simulation of discrete events and b) the simulation based on agents which used the AnyLogic ${ }^{\mathrm{TM}}$ software. Those characteristics are present in most of the analysed works, and as a measure of performance the use of the margin of the total contribution. The measure is able to represent not only the costs, but also the revenue from selling the products, which can be under the effect of the direct interference based on the number of additional operators available.

\subsection{The methodology of the research}

From [21], the modelling and the simulation research methodology are based on quantitative models and on the assumption that people can build objective models. The standards explain the behaviours of the real operational processes or capture a part or some parts of the decision-making problems faced by the managers during the development of those processes.

This work adopted the method for a simulation project proposed by Montevechi et al. [22]. According to this plan, a simulation project is divided into three phases, and each phase has a model of itself: the conception phase (conceptual model), the implementation phase (computer model) and the analysis phase (operational model). 


\section{APPLICATION OF THE MODELLING AND SIMULATION METHOD}

According to the research methodology, the first stage of the work was the conception phase, wherein the conceptual model of the system for the production of the Pupunha palm was developed. The intensive usage of the working force allied the necessity of independent arrangements to justify the choice of the company for this work and hybrid simulation. This company has a mix of the following types of products in its manufacture: Tolete trays, Chopped, Lasagne, Spaghetti and Carpaccio. The modelling and simulation of its production line involves the producing of new items such as Banda and Round Sliced.

The selected model supported the data collection by indicating the points wherein the data should be collected, thus facilitating the construction of the computational model. The mapping technique used in this phase is called IDEF-SIM and it was implemented on the software DIA ${ }^{\mathrm{TM}}$, as detailed in Figs. 2 to 5.

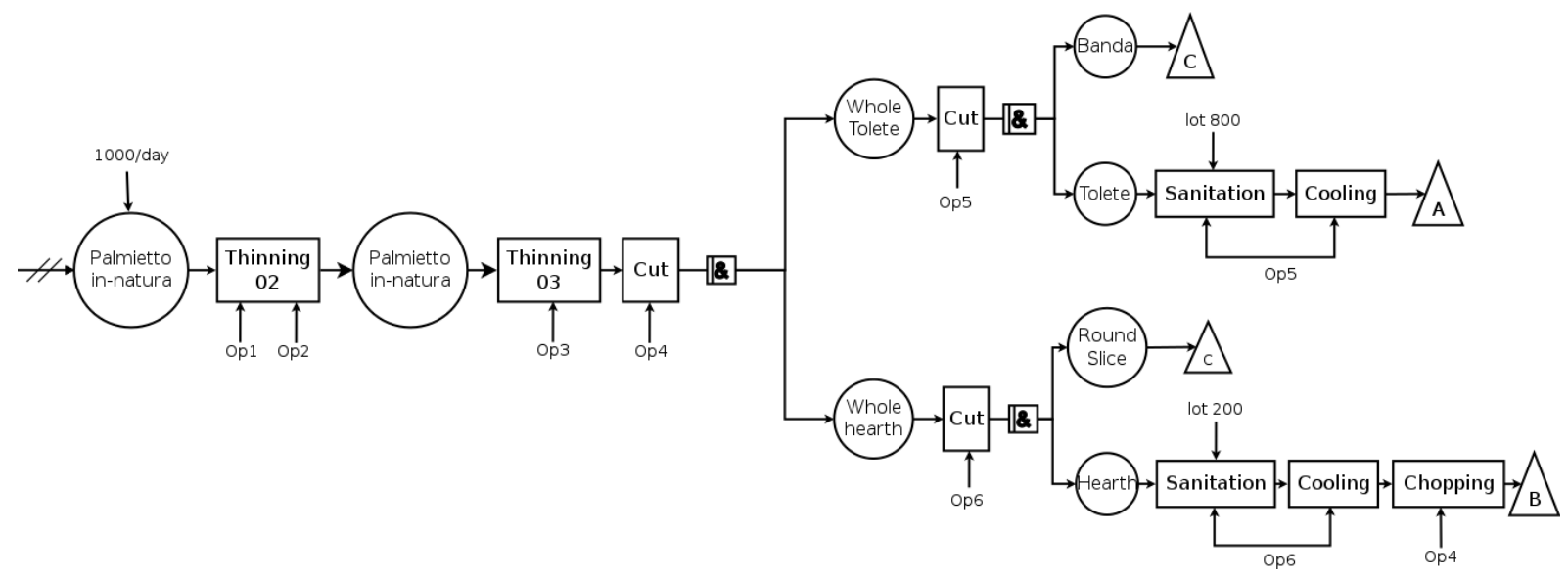

Figure 2: IDEF-SIM part 1.

The process begins with the arrival of the "Palmetto in natura" (i.e. fresh palm) entity, in a daily amount of 1,000 units. In this system (Figs. 2 and 3) there are: 11 different locations (Thinning 02 and 03, Cut, Sanitation, Cooling, Chopping, Packing, Salting wait, Filling, Cooking, and Quarantine); six resources (Operators Op1 to Op6); and 19 other entities (Palmetto, Whole Tolete, Whole Heart, Tolete, Banda, Round Slice, Heart, trays of Tolete, Chopped, Lasagne, Spaghetti, Carpaccio and jars of Banda, Tolete, Round Slice).

After the construction of the conceptual model, it was validated through the Face-to-Face technique by presenting it to the company's consultant. The data were acquired through filming and chronological analysis through timing the lead times of the process. The times for each location are presented in Table II. The values that are fixed show nearly automatic behaviour and their variations are not considered towards the average value. Thus, it was decided to use the standard time.

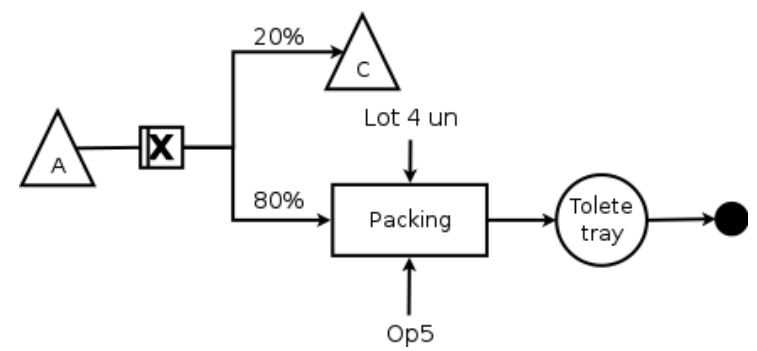

Figure 3: IDEF-SIM part 2. 


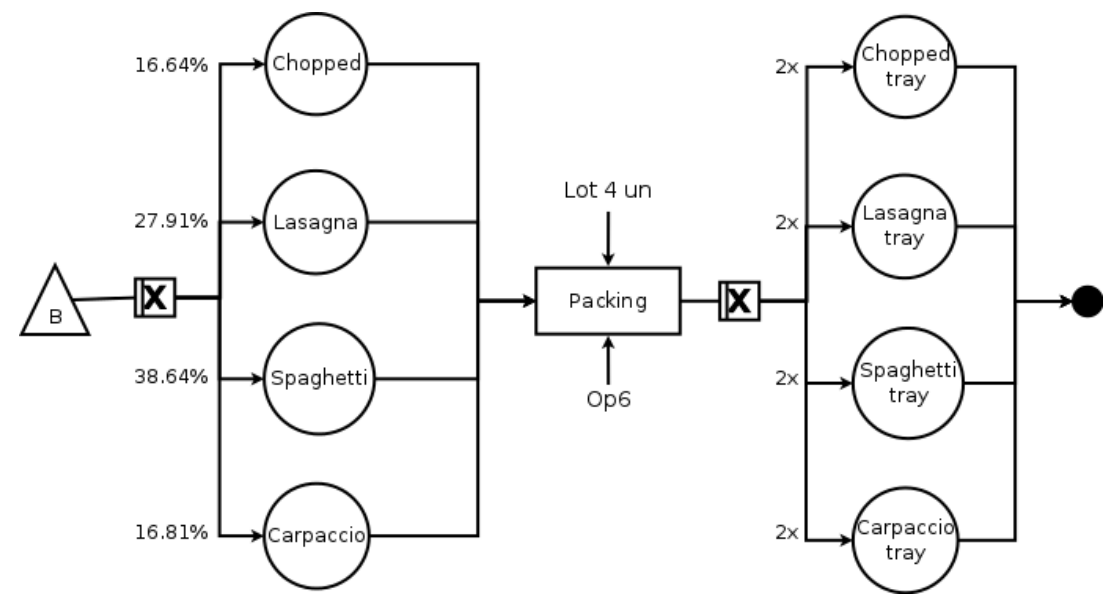

Figure 4: IDEF-SIM part 3.

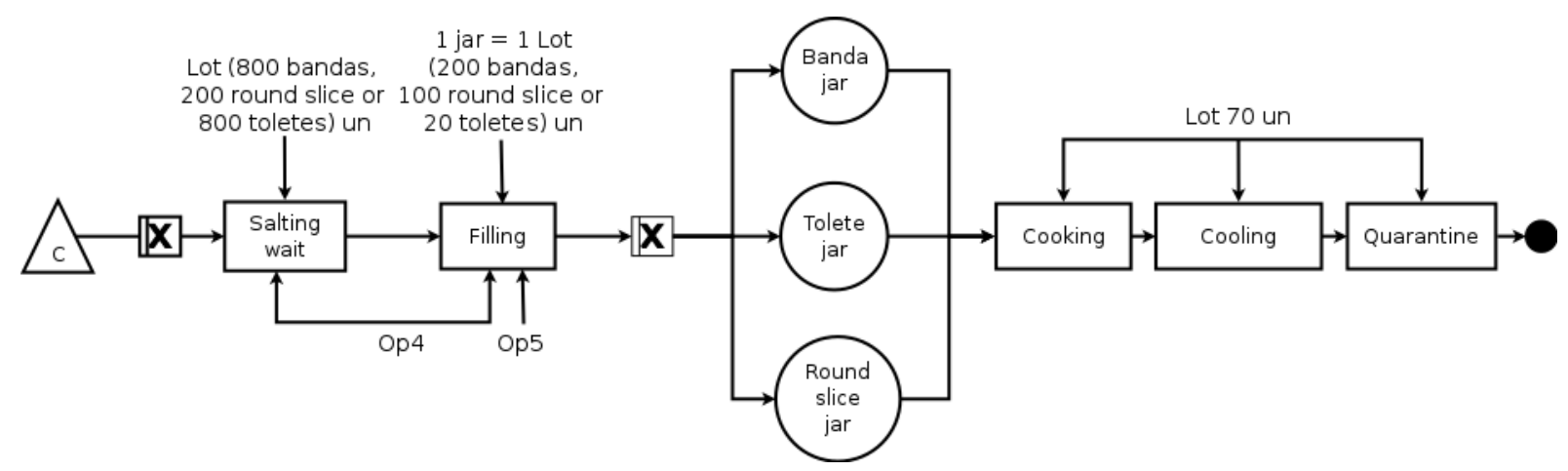

Figure 5: IDEF-SIM part 4.

Table II: Location times for the simulation.

\begin{tabular}{|l|c|}
\hline \multicolumn{1}{|c|}{ Location } & Time \\
\hline Thinning 02 & Normal $(52.00 ; 6.26) \mathrm{s}$ \\
\hline Thinning 03 & Normal $(24.45 ; 2.80) \mathrm{s}$ \\
\hline Cut & Normal $(27.03 ; 2.77) \mathrm{s}$ \\
\hline Tolete Cut & Normal $(14.52 ; 1.51) \mathrm{s}$ \\
\hline Heart Cut & Normal $(14.52 ; 1.51) \mathrm{s}$ \\
\hline Sanitation & $30 \mathrm{~min}$ \\
\hline Salting & $20 \mathrm{~min}$ \\
\hline Drying & $15 \mathrm{~min}$ \\
\hline Chopping & $30 \mathrm{~s}$ \\
\hline Packing & Normal $(65.30 ; 2.93) \mathrm{s}$ \\
\hline Tolete Packing & Normal $(50.84 ; 2.48) \mathrm{s}$ \\
\hline Filling & $3 \mathrm{~min}$ \\
\hline Cooling & $30 \mathrm{~min}$ \\
\hline Quarantine & $13 \mathrm{~d}$ \\
\hline
\end{tabular}

Then, the computer model was constructed using the AnyLogic ${ }^{\circledR} 7.0 .3$ software. The utilization of this software was due to the possibility of using a hybrid model (i.e., DES and ABM). The validation of the computational model was performed through the two-sample- $t$ statistical technique using Minitab ${ }^{\mathrm{TM}} 16$ software, by comparing the actual data of the number of trays produced per day with the simulated data. Then followed the assessing (with a confidence level of $95 \%$ ), if they are statistically equivalent. Firstly, in order to use the statistical test, the regularity of the real and fabricated data was guaranteed as well as the equality of their variants. 
The first hypothesis evaluated was if the model could be validated, that is, whether there was a statistical match between the simulation model and the actual data. The $P$-value of the two-sample- $t$ test was equal to 0.968 . Thus, with a confidence level of $95 \%$, the model was considered validated.

Later, a contribution margin $(C M)$ was used, comparable to the revenue of the selling and the variable costs during the time of the analysis as seen in Eq. (1). This index will serve as an indicator of comparison to evaluate the financial viability of the scenarios examined.

$$
C M=\sum_{i=1}^{5}\left(S P u_{i} * Q_{i}\right)-\sum_{i=1}^{5}\left(V C u_{i} * Q_{i}\right)-\left(O_{p} * 3795.68\right)
$$

where $i$ is the $i^{\text {th }}$ product; $Q_{i}$ is the amount produced by the product $i$ during the period; $S P u_{i}$ is the selling price of a unit of product $i$; $V C u_{i}$ is the variable cost of a unit of product $i$ and $O_{p}$ is the number of additional operators.

The value of $\$ 3,795.68$ corresponds to the expense of 62 days for each additional operator, and it is proportional to the simulation period. The value of 62 days corresponds to the cycle of the analysis of the company (approximately 2 months). The values of the sales revenues and variable costs are expressed in Table III.

Table III: Sales revenues and variable costs for each type of tray.

\begin{tabular}{|c|c|c|c|}
\hline $\boldsymbol{i}$ & Tray & $\boldsymbol{S P u}$ & $\boldsymbol{V C u}$ \\
\hline 1 & Carpaccio & $\$ 3.33$ & $\$ 1.16$ \\
\hline 2 & Tolete & $\$ 6.40$ & $\$ 4.06$ \\
\hline 3 & Spaghetti & $\$ 3.33$ & $\$ 1.16$ \\
\hline 4 & Lasagne & $\$ 3.33$ & $\$ 1.16$ \\
\hline 5 & Chopped & $\$ 3.33$ & $\$ 1.28$ \\
\hline
\end{tabular}

\subsection{Decision process}

The contribution of ABMS is to simulate the decision-making process of a hypothetical manager who will supervise the occupancy level of each workstation, as well as the size of the queue in each workstation. The available operators are represented by $O p X$, where $\mathrm{X}$ goes from 1 to 6.

Initially, every workstation starts working in the state "Working normally", and performs a verification of the situation at that moment by comparing one variable of the decision to the value of reference. Based on the case where a decision is determined by the size of the previous intermediate inventory, the alternative of the decision will be the size of the inventory where the value of reference is 500 units. For a different type of decision, the variable of the decision will be the rate of the average occupation of the working station, and its standard value is $80 \%$.

If the researchers perceive that the variable of decision has a value higher than the standard amount, then its state is changed to "Working Overloaded". Thus a message is sent to the manager referring to the situation. In turn, the manager, having the new information, makes certain if there is any additional worker available at this moment. If there is a vacant worker, he/she is guided to the station in need. Otherwise, the requisition keeps waiting in line until it is sorted out.

Note that the process will make a cyclical check every 10 minutes to verify the occupancy level or the size of the intermediate inventory for each $O p X$. This interval of verification will be changed to one hour if at least one additional operator is needed. The decision of the managers - according to the Working Normally or Overloaded status - is represented by a flowchart in Fig. 6. 
We chose ABS to implement the decision-making in the time of execution. This provides the justification of the usage of the hybrid simulation since it would be very difficult to supplement those decisions as a replica of strictly discrete events.

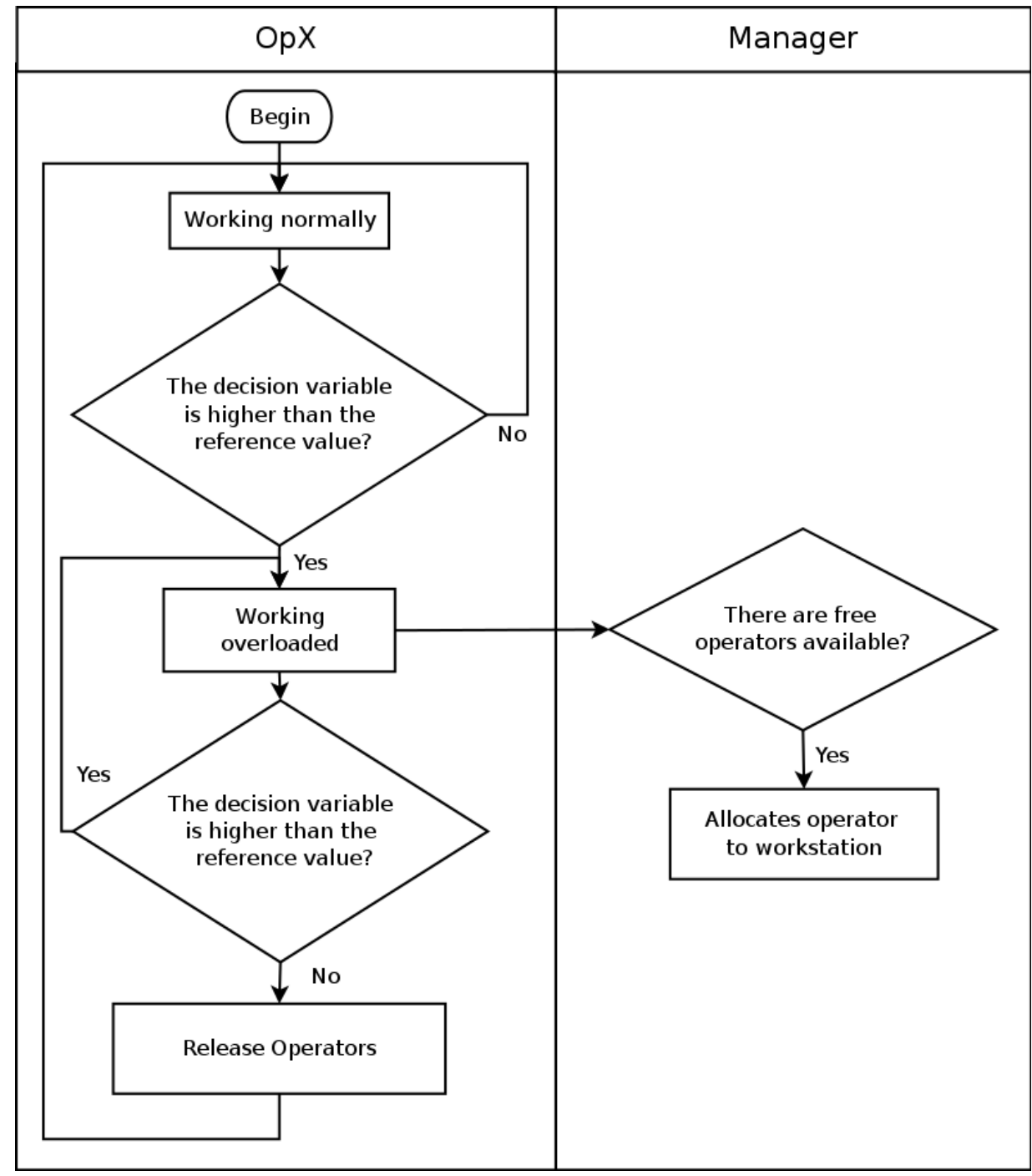

Figure 6: Decision process.

\section{RESULTS}

We will show in this part of the work the results of the simulation process based on the two types of decisions that were analysed. Initially, we had only one parameter, which is the quantity of additional operators varying from zero to five, within the experiments of simulation. There are two types of techniques of simulation related to the kind of decision. One option is considering the size of the intermediary inventory. When this stock indicates a value equal to or greater than 500 units, a demand of an additional operator is created for the manager. When the decision is taken at the level of occupation in the workstation, the decision is made when the rate has a value equal to or greater than $80 \%$.

\subsection{Primary results}

We performed 12 simulation experiments for each decision-making process based on the occupancy levels at the workstation by considering 0 to 5 additional operators and the intermediate inventory size. Fifty replicates were executed for each experiment. 
The descriptive statistics of those 12 scenarios are presented in Table IV and Table V, and in Figs. 7 and 8, which show the boxplot graphics of the resulted margin of contribution.

Table IV: Decision, based on the level of occupancy.

\begin{tabular}{|c|c|c|}
\hline Number of additional operators & Margin of the Average Contribution & Standard Deviation \\
\hline 0 & $\$ 118,845.66$ & $\$ 314.86$ \\
\hline 1 & $\$ 151,745.04$ & $\$ 4,590.68$ \\
\hline 2 & $\$ 121,002.35$ & $\$ 4,679.42$ \\
\hline 3 & $\$ 122,698.97$ & $\$ 13,485.96$ \\
\hline 5 & $\$ 118,364.63$ & $\$ 3,886.36$ \\
\hline$\$ 105,502.45$ & $\$ 6,535.00$ \\
\hline
\end{tabular}

Table V: Decision on the size of the intermediate inventory.

\begin{tabular}{|c|c|c|}
\hline Number of additional operators & Margin of the average contribution & Standard Deviation \\
\hline 0 & $\$ 118,797.78$ & $\$ 285.23$ \\
\hline 1 & $\$ 115,053.71$ & $\$ 263.70$ \\
\hline 2 & $\$ 134,527.83$ & $\$ 6,547.94$ \\
\hline 3 & $\$ 160,930.33$ & $\$ 20,878.64$ \\
\hline 4 & $\$ 223,828.95$ & $\$ 23,983.45$ \\
\hline 5 & $\$ 258,393.56$ & $\$ 24,462.52$ \\
\hline
\end{tabular}

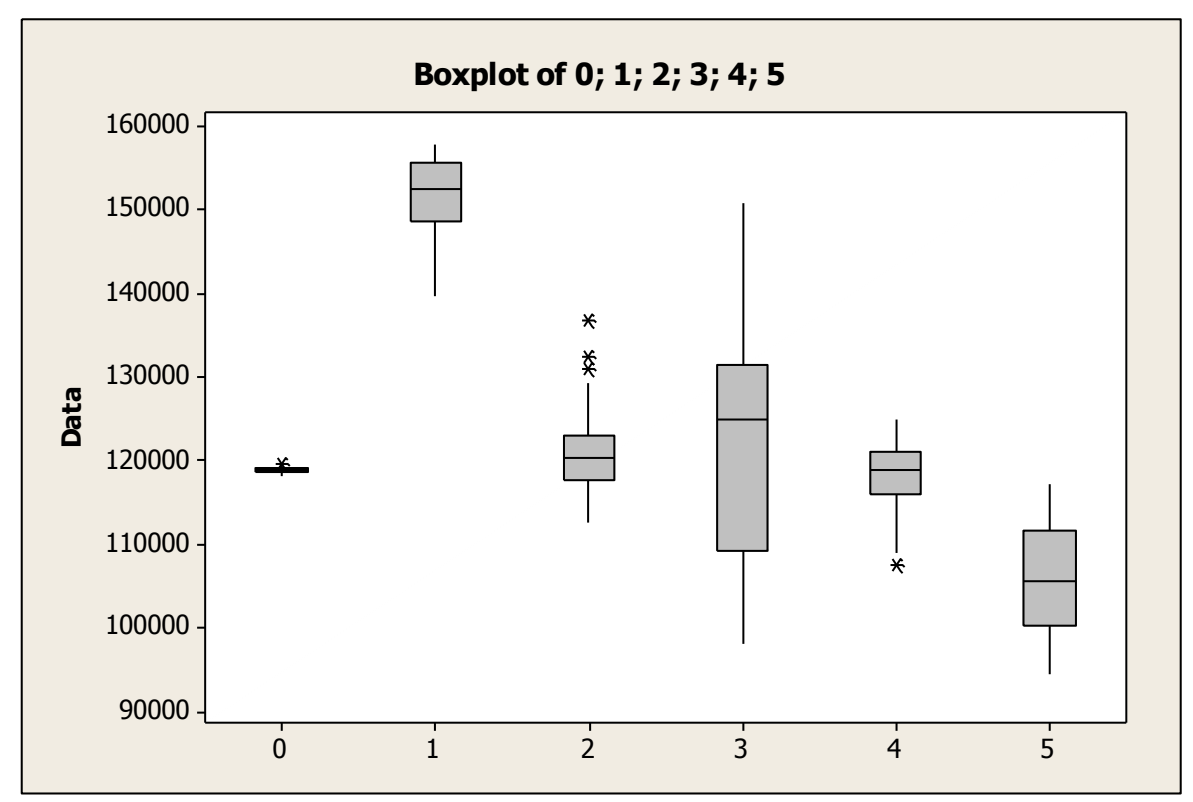

Figure 7: Decision by the level of occupancy.

Here, two distinct situations are observed (Figs. 7 and 8). For the first case, where the decision criterion is based on the workstation occupancy level, there is statistical evidence when using test $t$ of an improvement on the financial index with the addition of auxiliary operators. Moreover, at the second table, the two-sample- $t$ test showed that the addition of one, two or three operators increases the value of the financial index. The test also showed that the inclusion of only one operator is better than the other two options. On average, the margin of contribution increased on average from $\$ 118,846.00$ to $\$ 151,745.00$.

A practical explanation for these results is that the more operators available, the lower the occupancy level of a workstation. There were cases where, despite the low occupancy level of the workstation, the additional operator remained idle for a period of one hour. 


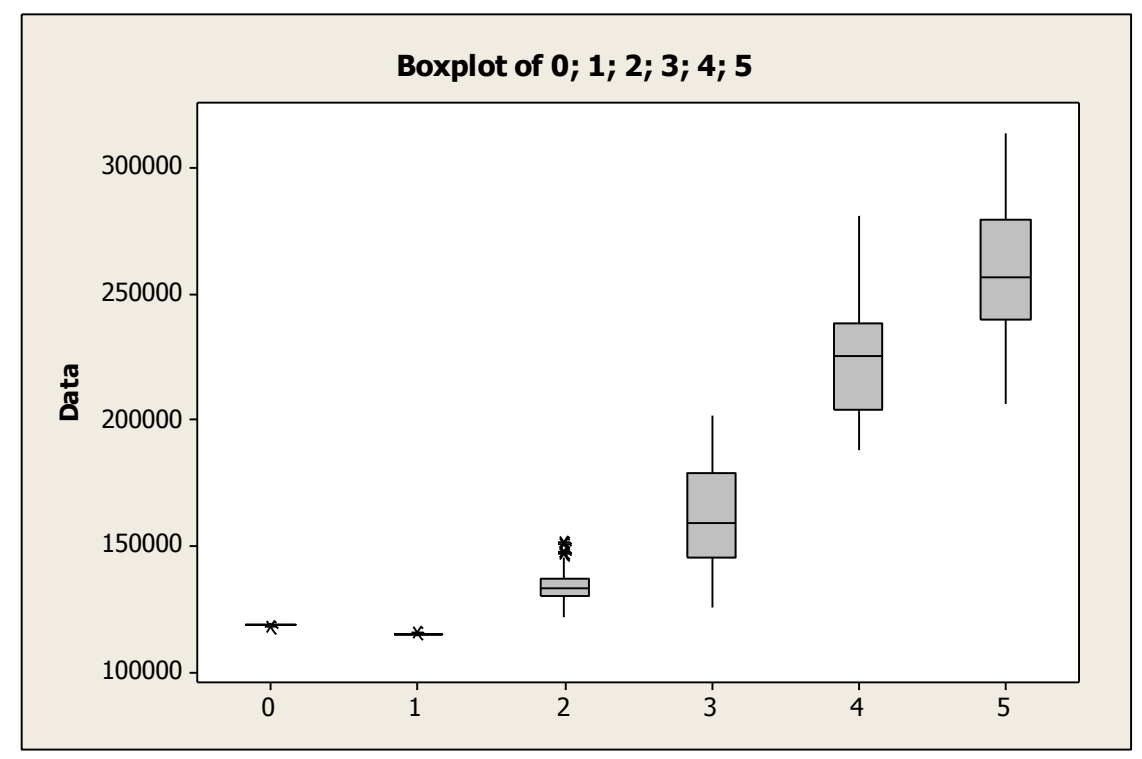

Figure 8: Decision by the size of the inventory.

Different from Figs. 7 and 8 we can see that by changing the manager's model of decision when there is an increase of additional operators, the financial index tends to follow this increase. Statistically, the two-sample- $t$ showed that only in the situation where there was an addition of one operator, there was no improvement in the space of contribution. In addition, among the remaining situations, the inclusion of 5 additional operators was the best fit. On average, the margin of contribution increased from $\$ 118,846.00$ to $\$ 258,394.00$.

We performed a comparison of individual values of the minimal constant of additional workers between the two types of decisions. Each analysis showed that the $p$-values presented a zero value, which indicates a significant difference when it comes to the type of decision to be chosen. The results confirmed that the decision based on the rate of occupancy is only statistically better than the resolution counted on the intermediate inventory when there is just one supplementary operator.

\section{CONCLUSIONS}

The results aimed at establishing a more adequate method of decision making for the temporary supply of additional operators, i.e. which method represented a significant impact on the margin of the total contribution during the 62 days of the experiment, and without altering other variables of the system. Thus, we used the hybrid replica of discrete events and the agents, which captures the behaviour of the discrete process in a way that captures the model of the real time decision of a manager of the company.

Observe the first analysis, in which the possible number of additional workforce was incrementally altered thus fixing the model of decision. This means $80 \%$ for the rate of occupancy in the workstation and 500 units for the intermediate inventory. These results indicate that if the number of additional workers was 1 , the best choice is the decision regarding the rate of occupants at the workstation. Therefore, when considering the other options with 2, 3, 4 or 5 additional operators, a good choice is the decision based on the size of the intermediate stock that is previously antecedent to the workstation.

However, when the workstation has just one operator available, the alternative of the decision based on the level of occupation of the workplace provides an opportunity for another data point to be watched, i.e. the routine analysis of the volume of the intermediary inventory is more practical in empirical terms. We verified that if some facilities had a level of occupancy higher than the others did, this enables them to ask for more additional workers 
continually, but the production did not have the same proportion. Based on the occupancy rate, the ratio improved on average $27.68 \%$ with an additional operator at the workstation. According to the second criterion, this improvement raised to $117.51 \%$.

We propose for future work the use of different types of optimization for the hybrid simulation. This is a new field of science, thus it deserves more attention beyond the variations of frameworks or the meta-heuristics, such as some modifications in the real time of the variables that may affect the process. For example, the intermediate inventory size and the rate of occupancy in the workstation based on the theory of production control.

Finally, it is worth highlighting that working with human aspects involves more knowledge than just the logical, analytical and computational facets. It is also noticeable that the aspects that were left out, such as the psychological, cultural conditions, among others, directly affect the productivity of the employees of the company.

\section{ACKNOWLEDGEMENTS}

The authors thank FAPEMIG, CAPES, and CNPQ for the support during the development of this research and for reviews.

\section{REFERENCES}

[1] Chwif, L.; Banks, J.; de Moura Filho, J. P.; Santini, B. (2013). A framework for specifying a discrete-event simulation conceptual model, Journal of Simulation, Vol. 7, No. 1, 50-60, doi: $10.1057 /$ jos.2012.18

[2] North, M. J.; Macal, C. M. (2007). Managing Business Complexity: Discovering Strategic Solutions with Agent-Based Modeling and Simulation, Oxford University Press, Inc., New York

[3] Bonabeau, E. (2002). Agent-based modeling: Methods and techniques for simulating human systems, Proceedings of the National Academy of Sciences of the United States of America, Vol. 99, No. Suppl. 3, 7280-7287, doi:10.1073/pnas.082080899

[4] Lucas, T. W.; Sanchez, S. M. (2002). Exploring the world of agent-based simulations: simple models, complex analyses, Proceedings of the 2002 Winter Simulation Conference, Vol. 1, 116126, doi:10.1109/WSC.2002.1172875

[5] Komma, V. R.; Jain, P. K.; Mehta, N. K. (2007). Agent-based simulation of a shop floor controller using hybrid communication protocols, International Journal of Simulation Modelling, Vol. 6, No. 4, 206-217, doi:10.2507/IJSIMM06(4)2.096

[6] Zhang, H. P. (2015). An agent-based simulation model for supply chain collaborative technological innovation diffusion, International Journal of Simulation Modelling, Vol. 14, No. 2, 313-324, doi:10.2507/IJSIMM14(2)CO6

[7] Law, A. M.; Kelton, W. D. (2000). Simulation modeling and analysis, $3^{\text {rd }}$ edition, McGraw Hill, Boston

[8] Sargent, R. G. (2014). Verifying and validating simulation models, Proceedings of the 2014 Winter Simulation Conference, 118-131, doi:10.1109/WSC.2014.7019883

[9] O'Kane, J. F.; Spenceley, J. R.; Taylor, R. (2000). Simulation as an essential tool for advanced manufacturing technology problems, Journal of Materials Processing Technology, Vol. 107, No. 1-3, 412-424, doi:10.1016/S0924-0136(00)00689-0

[10] Banks, J.; Carson II, J. S.; Nelson, B. L.; Nicol, D.M. (2005). Discrete-event system simulation, $4^{\text {th }}$ edition, Pearson Prentice Hall, Upper Saddle River

[11] Macal, C. M.; North, M. J. (2013). Introductory tutorial: agent-based modeling and simulation, Proceedings of the 2013 Winter Simulation Conference, 362-376, doi:10.1109/WSC.2013.6721434

[12] Macal, C. M. (2016). Everything you need to know about agent-based modelling and simulation, Journal of Simulation, Vol. 10, No. 2, 144-156. doi:10.1057/jos.2016.7

[13] Mortazavi, A.; Arshadi Khamseh, A.; Azimi, P. (2015). Designing of an intelligent self-adaptive model for supply chain ordering management system, Engineering Applications of Artificial Intelligence, Vol. 37, 207-220, doi:10.1016/j.engappai.2014.09.004 
[14] Hao, Q.; Shen, W. (2008). Implementing a hybrid simulation model for a Kanban-based material handling system, Robotics and Computer-Integrated Manufacturing, Vol. 24, No. 5, 635-646, doi:10.1016/j.rcim.2007.09.012

[15] Zhao, J.; Mazhari, E.; Celik, N.; Son, Y.-J. (2011). Hybrid agent-based simulation for policy evaluation of solar power generation systems, Simulation Modelling Practice and Theory, Vol. 19, No. 10, 2189-2205, doi:10.1016/j.simpat.2011.07.005

[16] Wang, W.; Fu, W.; Zhang, H.; Wang, Y. (2013). Hybrid modeling and simulation of automotive supply chain network, Research Journal of Applied Sciences, Engineering and Technology, Vol. 6, No. 9, 1598-1605

[17] Suh, E. S. (2015). Cross-docking assessment and optimization using multi-agent co-simulation: a case study, Flexible Services and Manufacturing Journal, Vol. 27, No. 1, 115-133, doi: $10.1007 / \mathrm{s} 10696-014-9201-3$

[18] Mittal, A.; Krejci, C. C. (2015). A hybrid simulation model of inbound logistics operations in regional food supply systems, Proceedings of the 2015 Winter Simulation Conference, 15491560, doi:10.1109/WSC.2015.7408276

[19] Onggo, B. S. (2014). Elements of a hybrid simulation model: a case study of the blood supply chain in low- and middle-income countries, Proceedings of the 2014 Winter Simulation Conference, 1597-1607, doi:10.1109/WSC.2014.7020011

[20] Wang, B.; Brême, S.; Moon, Y. B. (2014). Hybrid modelling and simulation for complementing lifecycle assessment, Computers \& Industrial Engineering, Vol. 69, 77-88, doi:10.1016/ j.cie.2013.12.016

[21] Bertrand, J. W. M.; Fransoo, J. C. (2002). Operations management research methodologies using quantitative modeling, International Journal of Operations \& Production Management, Vol. 22, No. 2, 241-264, doi:10.1108/01443570210414338

[22] Montevechi, J. A. B.; Leal, F.; De Pinho, A. F.; Da Silva Costa, R. F.; Moura De Oliveira, M. L.; Faustino Da Silva, A. L. (2010). Conceptual modeling in simulation projects by mean adapted IDEF: an application in a Brazilian tech company, Proceedings of the 2010 Winter Simulation Conference, 1624-1635, doi:10.1109/WSC.2010.5678908 